\section{Addendum: Butterfly effect and a self- modulating El Niño response to global warming}

https://doi.org/10.1038/s41586-021-03261-4

Addendum to: Nature https://doi.org/10.1038/s41586-020-2641-x

Published online 02 September 2020

Check for updates

Wenju Cai, Benjamin Ng, Tao Geng, Lixin Wu, Agus Santoso \&

Michael J. McPhaden

In this Article, we demonstrated that the El Niño-Southern Oscillation (ENSO) response to greenhouse warming is self-modulating and depends on its historical variability, partly by a negative interexperiment correlation between initial ENSO variability and its initial-to-future change. Since publication, it has come to our attention that initial variability correlated with the difference between itself and its future value will tend to be, by definition, anti-correlated. Furthermore, an anti-correlation between initial and future variability can be amplified by using a normalized time series, such as the normalized $E$-index described in our Article. For example, when the standard deviation in the initial period is amplified by internal variability, this also amplifies the standard deviation for the whole time series (assuming an average level of variability after the initial period). This increases the normalization coefficient, and thus reduces the normalized standard deviation for the future period. As such, the strong anti-correlations in Fig. 1b, c and 4 of our original Article are, in part, contributed by the statistical formulation.

Here we reformulate the analysis to avoid these statistical issues. By using raw sea surface temperature (SST) anomalies from large ensemble experiments of the three different models-the Community Earth System Model (CESM), the Geophysical Fluid Dynamics Laboratory Climate Model version 3 (GFDL-CM3) and Geophysical Fluid Dynamics Laboratory Earth System Model second model (GFDL-ESM2M))we show that the connection between the twentieth-century and twenty-first-century ENSO variability is still present (Fig. 1). The variability of quadratically detrended SST anomalies at the geographical centre of eastern Pacific ENSO shows that experiments that generate greater initial variability produce smaller future variability and therefore a smaller increase. The relationship is statistically significant above the $95 \%$ or $90 \%$ confidence level (Fig. 1). The correlation from the direct SST anomalies $(r=-0.33$ to -0.42$)$ avoids any statistical artefacts and is fundamental to the result expressed in Fig. $1 \mathrm{~b}, \mathrm{c}$ and 4 of the original Article. The interexperiment relationship in our Article indicates that the initial variability explains about $60 \%$ of the future-minus-initial change in variability. With the revised approach, the initial variability explains $10-18 \%$ of future variability, with the remainder being attributed to other factors including the effect of stochastic forcing, such as atmospheric noise, which is compounded throughout the evolution of the twenty-first century. The butterfly effect is expected to operate among the members of the Coupled Model Intercomparison Project (CMIP) multi-model ensemble, despite the large inter-model
Initial and future SST variability

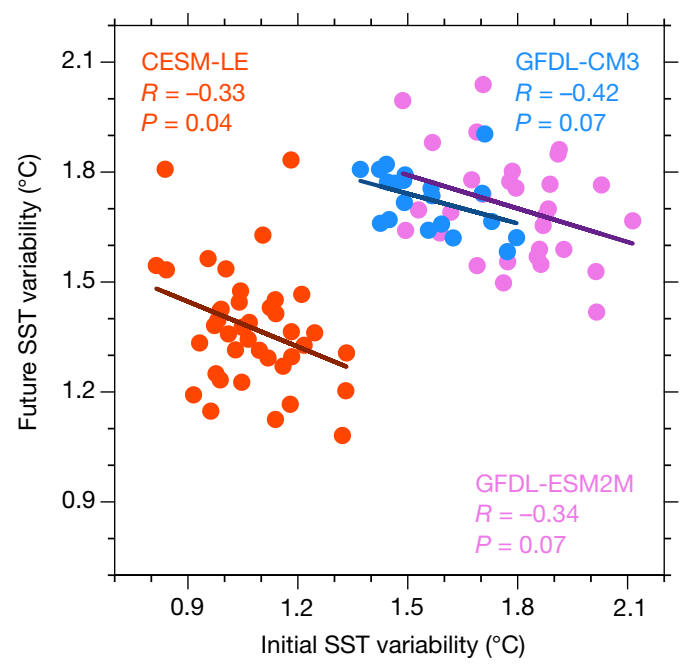

Fig. 1 | Connection between twentieth-century and twenty-first century ENSO variability. The variability of quadratically detrended SST anomalies $\left({ }^{\circ} \mathrm{C}\right)$ from 40, 20 and 30 large ensemble experiments using the CESM-LE, GFDLCM3 and GFDL-ESM2M, respectively, all under historical forcing (up to 2005) and thereafter the representative concentration pathway 8.5 (RCP8.5) scenario (up to 2099). There is an anti-correlation between the initial and future 50-year SST s.d. values over the equatorial Pacific region where the $E$-index peaks, which is statistically significant above the $95 \%$ or $90 \%$ confidence level. These centres are: $2^{\circ} \mathrm{S}-2^{\circ} \mathrm{N}, 100^{\circ} \mathrm{W}-110^{\circ} \mathrm{W}$ for CESM-LE; $2^{\circ} \mathrm{S}-2^{\circ} \mathrm{N}, 111^{\circ} \mathrm{W}-121^{\circ} \mathrm{W}$ for GFDL-CM 3 ; and $2^{\circ} \mathrm{S}-2^{\circ} \mathrm{N}, 104^{\circ} \mathrm{W}-114^{\circ} \mathrm{W}$ for GFDL-ESM2M. The initial and future 50-year periods are 1920-1969 and 2050-2099 for CESM-LE and GFDL-CM3, and 1950-1999 and 2000-2049 for GFDL-ESM2M.

differences in the ENSO variability due to various factors such as model physics and climate sensitivity. This is underscored by the comparable inter-model spread in the initial-to-future trend of ENSO variability between the CMIP multi-model ensemble and the single-model CESM large ensemble-the future-minus-initial standard deviation in Niño3.4 ( $E$-index) variability for the CMIP ensemble is $0.27^{\circ} \mathrm{C}(0.32 \mathrm{s.d}$.$) , and$ $0.18^{\circ} \mathrm{C}(0.24$ s.d.) for the CESM-LE-thus indicating a substantial contribution of internal variability to the CMIP inter-model differences in the ENSO variability trend.

The mechanisms presented in our original Article are also robust regarding the use of raw data. For example, the nonlinear relationship between the eastern Pacific SST anomalies and the net heat flux damping that underpins ENSO nonlinear thermodynamics shown in Fig. 2a of this Amendment is similar to that in Fig. 2a of the original Article. The relationship indicates that thermal damping during an $\mathrm{El}$ Niño is stronger than that during a La Niña, and represents an anomalous oceanic heat loss and atmospheric heat gain, respectively. Thus, experiments with stronger initial SST variability produce stronger cumulative heat loss in the central-to-eastern equatorial Pacific over the initial 50 years (see Fig. 2b, c; compare with Fig. 2d, e of the original Article), and the anomalous cooling eventually reaches the upper equatorial Pacific (see Fig. 2d; compare with Fig. 3c of the original Article), leading to a smaller warming. This anomalous cooling offsets the greenhouse-warming-induced intensification of stratification in the upper ocean that otherwise facilitates a stronger increase in ENSO variability.

In summary, although our main conclusion on the link between twentieth-century and twenty-first-century ENSO variability remains qualitatively consistent, the magnitude of the relationship is considerably reduced from what the original anti-correlations between initial variability and its future change might suggest. We thank J. Räisänen for bringing this to our attention, and are grateful for his open, detailed and constructive feedback. The original Article has not been corrected. 

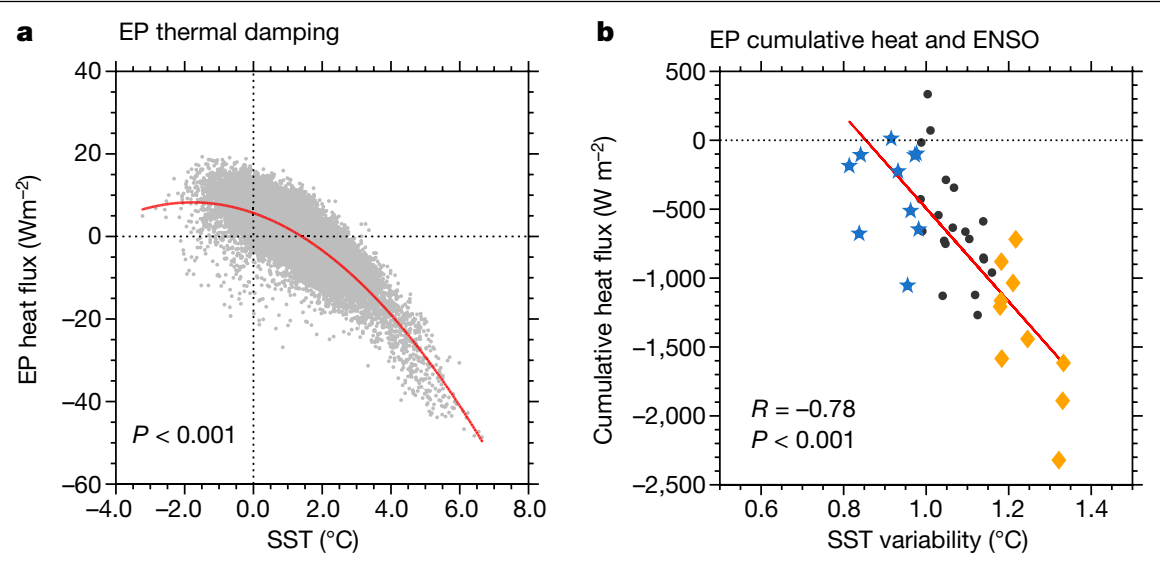

C
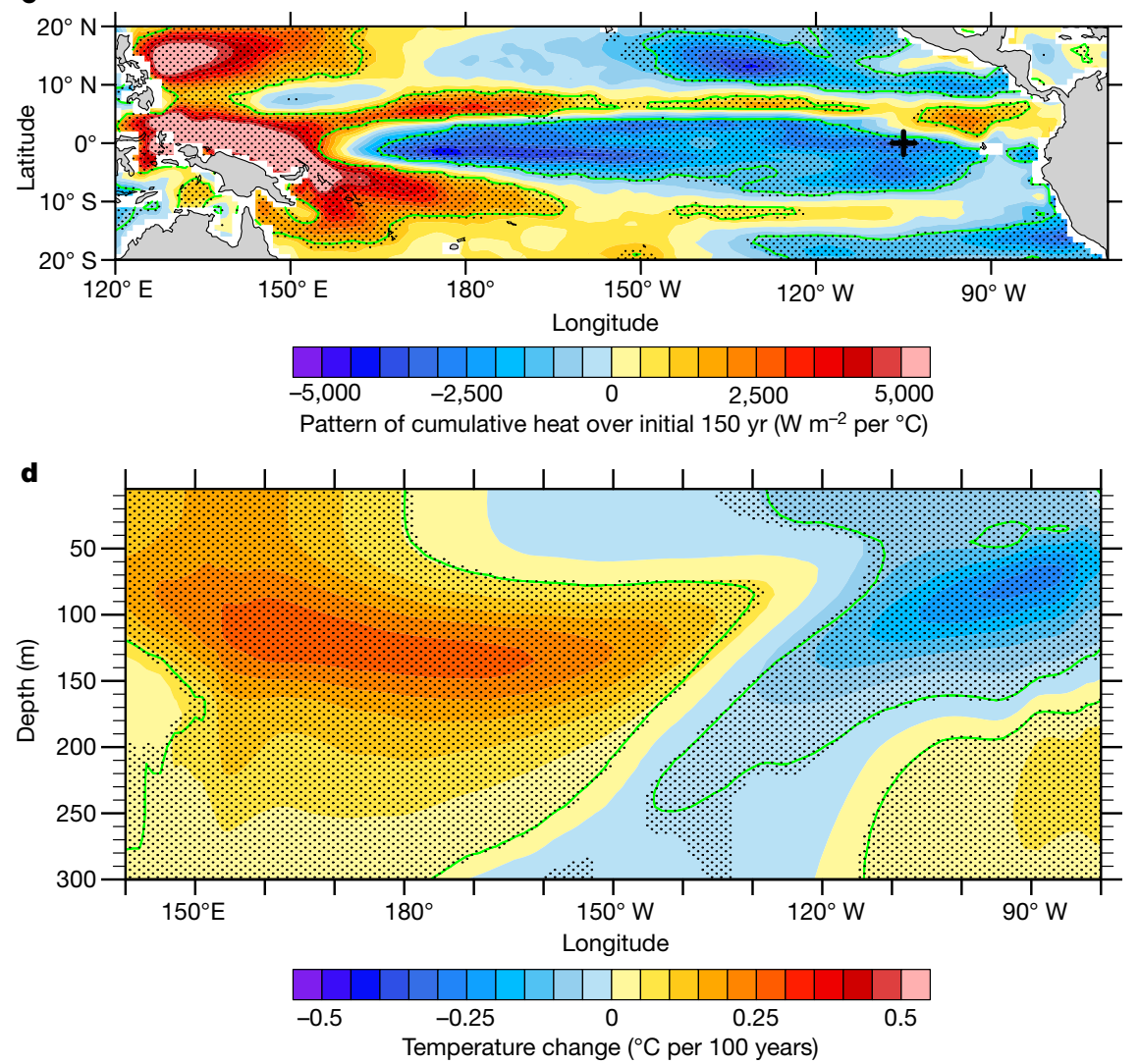

Fig. 2 | Mechanism linking initial and future ENSO variability through ENSO nonlinear thermal damping. The results from the CESM-LE experiments. a, Relationship between the monthly SST in which the $E$-index peaks $\left(2^{\circ} \mathrm{S}-2^{\circ} \mathrm{N}, 100^{\circ} \mathrm{W}-110^{\circ} \mathrm{W}\right)$ and net heat flux over the eastern Pacific $\left(\mathrm{EP}, 5^{\circ} \mathrm{S}-5^{\circ} \mathrm{N}\right.$, $\left.150^{\circ} \mathrm{W}-90^{\circ} \mathrm{W}\right)$. b, Interexperiment relationship between the eastern Pacific SST variability (1920-1969) and cumulative ocean heat loss $\left(\right.$ at $0^{\circ}, 105^{\circ} \mathrm{W}$, indicated by a black cross in c). The blue stars and orange diamonds represent the ten experiments with the weakest and strongest initial eastern Pacific SST variability $\left({ }^{\circ} \mathrm{C}\right)$, respectively. Solid black circles represent other experiments. c, Interexperiment regression of 40 cumulative heat flux fields onto 40 values of SST variability $\left({ }^{\circ} \mathrm{C}\right)$ in which the $E$-index peaks $\left(2^{\circ} \mathrm{S}-2^{\circ} \mathrm{N}, 100^{\circ} \mathrm{W}-110^{\circ} \mathrm{W}\right)$ over the initial 50 years (1920-1969), showing an ENSO pattern of cumulative

heat flux. Statistical significance above the $90 \%$ and $95 \%$ confidence levels based on a two-tailed Student's $t$-test is indicated as black stippling and green solid contours, respectively. d, Difference in linear trends of mean ocean temperature of the equatorial Pacific (average over $5^{\circ} \mathrm{S}-5^{\circ} \mathrm{N}$ ) over the first 150 years, between the average of ten experiments with strongest and weakest initial SST variability $\left({ }^{\circ} \mathrm{C}\right)$, indicating eventual cooling of the eastern equatorial Pacific. The anomalous cooling, stemming from cumulative heat loss generated since the initial period of strong ENSO variability, weakens greenhouse-warming-induced enhancement of stratification in the upper equatorial Pacific, and leads to a smaller increase in ocean-atmosphere coupling and thus a weaker future increase in ENSO variability. 